\title{
Review of Technologies and Optimisation Methods for Integrating Renewable Energy Sources and Storage Within the Australian National Energy Market
}

\author{
$\underline{\text { L. R. Cirocco, }}{ }^{\mathrm{a}}$ P. Pudney, ${ }^{\mathrm{a}}$ M. Belusko, ${ }^{\mathrm{b}}$ F. Bruno, ${ }^{\mathrm{b}}$ J. Boland ${ }^{\mathrm{a}}$ \\ ${ }^{a}$ Centre for Industrial and Applied Mathematics, \\ School of Information Technology and Mathematics and Barbara Hardy Institute, \\ University of South Australia, Mawson Lakes Boulevard, Mawson Lakes, SA, 5095, Australia \\ ${ }^{\mathrm{b}}$ School of Engineering and Barbara Hardy Institute, University of South Australia, Australia \\ Email: luigi.cirocco@mymail.unisa.edu.au
}

\begin{abstract}
Renewable energy generators such as Concentrated Solar Thermal (CST), Photovoltaic (PV), wind, wave and tidal power do not always generate power when it is needed, and so there is an increasing need for energy storage. For thermal systems, the storage could be thermal energy storage at the generator or electrical storage at the generator or within the electrical network.

With the proliferation of non-scheduled generation from renewable electrical energy sources such as there is an ever present need for enabling scheduled generation via the incorporation of energy storage; either as from directly coupled Thermal Energy Storage (TES) at the source or distributed Electrical Storage Systems (ESS) within the electrical network or grid.

The aims of this paper are twofold: to review the existing and emergent storage technologies and to survey the most appropriate optimisation techniques in determining the storage size and the subsequent optimal operation of the system within the context of the Australian National Energy Market (NEM).

Firstly, a review for storage technologies is performed to establish sources for indicative characterisations of energy density, storage containment, conversion efficiency, charge/discharge rates and associated costing.

The survey of optimisation techniques is partitioned into those methods most appropriate for various time scales. That is, from "whole of year", seasonal, monthly, weekly and daily averaging to those best suited matching the Australian National Energy Market bid timing of five minute dispatch pricing, which is then averaged on the half hour to determine the spot price for trading settlement.

The paper concludes with the selection of what we believe to be the most promising research directions to determine the optimal sizing and operation of storage within the grid for scheduled generation from renewable electrical energy sources.
\end{abstract}

Keywords: Thermal Storage, Electrical Storage Systems, Optimisation, Five Minute Bidding, Half Hour Trading Cycle 


\section{INTRODUCTION}

In Australia, Concentrated Solar Thermal (CST) plants, which convert concentrated sunlight to heat and then to electricity, have the potential to be a substantial contributor of electricity generation. These plants usually incorporate some means of storing any heat that is not immediately converted into electricity in what is termed Thermal Energy Storage (TES); this stored heat can then be used to generate electricity at other times such as when it is cloudy or at night.

With growing levels of renewable energy generation, including wind farms and residential rooftop photovoltaic systems maintaining grid stability is emerging as a critical problem in the short term. However, research into optimal operation of solar thermal plants and optimal sizing of storage is still in its infancy.

Furthermore, research into hybridised storage for CST which incorporates both thermal and electrical storage controlled from the one CST plant is also lacking despite extensive research into electrical storage options for other variable generation, renewable energy sources such as wind and PV generation.

Electrical storage has a greater cost than thermal storage, but may nevertheless play an important role in handling rapid fluctuations in demand or supply. This paper considers the incorporation of electrical storage with a solar thermal plant as it may still prove advantageous despite there being little or no identified literature considering a solar thermal plant with both thermal and electrical storage within its control.

Figure 11 depicts a generalised solar thermal plant that incorporates thermal energy storage with electrical heaters and electrical energy storage in the plant design. Such a plant would then participate in the supply of electricity to the grid within the Australian National Energy Market (NEM), bidding for the generation of power and associated services in accordance with the National Electricity Rules (AEMC, 2013). Essentially this market requires bids for the dispatch of energy to be placed every 5 minutes, with the spot price to be paid to suppliers by consumers being the average of the last 6 bids as cleared every half hour.

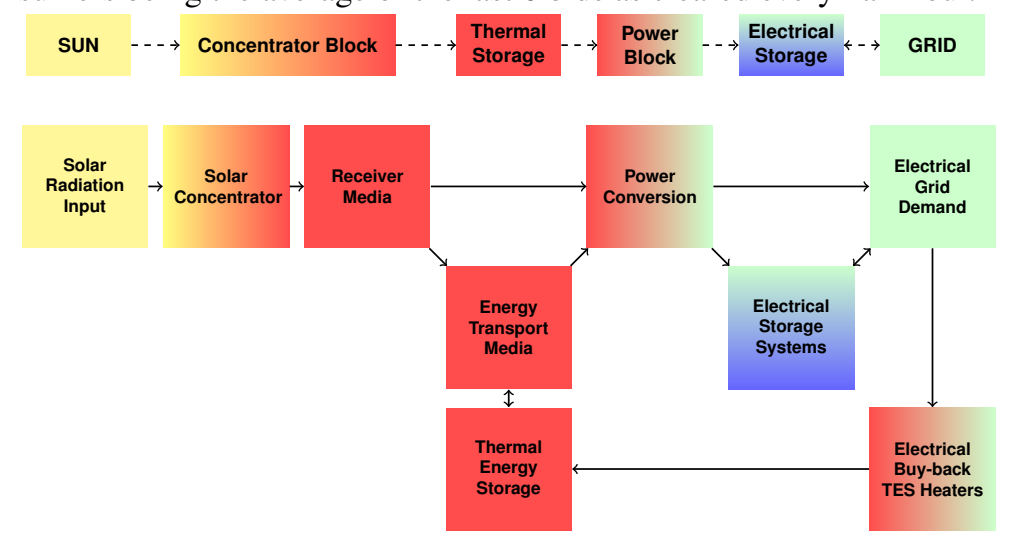

Figure 1. General Overview of Energy Conversion Blocks for Concentrated Solar Power, adapted from Lovegrove and Pye (2012) and Morin (2012)

The remainder of this paper is segmented into two main parts: Section 2 presents a brief overview of renewable energy technologies with a focus on concentrated solar collection, thermal and electrical storage, as depicted in Figure 1. Section 3 presents a survey of modelling, optimization and control methods relating to CST with storage. Concluding remarks and future research directions are given in Section 4.

\section{Technologies for Renewable Energy Generation and Storage}

This section provides a sampling of the literature for descriptions of the various CST technologies and on the use of thermal and electrical storage with renewable energy generators.

Within the broad domain of renewable energy generation there are number of sub-domains; the collection preface by Sayigh (2012) presents a partitioning of these sub-domains as follows: i) Photo-Voltaic, ii) Wind, iii) Solar Thermal, iv) Fuel Cells and Hydrogen Technology, v) Biomass and Biofuels, vi) Hydro, vii) Geothermal and viii) Oceanic Power. CST is then treated as one element of the "solar thermal" grouping.

Hoffschmidt et al. (2012) presents an overview of the variety of CST implementations, with Lovegrove and Pye (2012) further detailing some of the theoretical limits on receiver topologies, of which there are four main types: i) Linear Fresnel Receiver, ii) Parabolic Trough, iii) Central Tower Receiver and iv) Paraboloid Dish Receiver. 
Overviews of thermal energy storage are presented by Cabeza (2012) and Steinmann (2012) with the various thermal storage technologies falling into one of the following categories: i) Sensible, ii) Latent or Phase Change Materials (PCM) and iii) Thermochemical. In general, sensible thermal storage is the least expensive per unit energy stored but also the least energy dense per unit volume with two tank molten salt systems being commercially deployed in a number of locations worldwide. PCM as formulated by Belusko et al. (2012) offers improvements in energy density but incurs higher per unit cost. Thermochemical storage using ammonia has the potential to offer the greatest energy density of all and is a topic of broad research but commercially viable systems have not yet been implemented (Lovegrove et al., 2004).

PV and wind can only utilise electrical storage systems and as such there is a large body of knowledge with Fthenakis and Nikolakakis (2012) providing a more general overview and the reviews by Díaz-González et al. (2012) and Chen et al. (2009) being more detailed. Like TES, ESS can be partitioned into three categories: i) Electro-mechanical, e.g. Pumped Hydro Storage (PHS), ii) Electro-chemical, e.g. Batteries and Capacitors and iii) Electro-magnetic, i.e. Superconductor Magnetic Energy Storage (SMES).

CST plants use conventional steam turbine driven electrical power generators. Some CST designs have hybridised the heat sources to incorporate heating elements which burn either a mineral gas or biofuel, enabling the plant to operate for a larger proportion of time especially during times of low irradiation i.e. winter days. An analysis of such a plant is presented by Usaola (2012a).

Lizarraga-Garcia et al. (2013) detail an implementation of CST with electrical buy-back heaters fitted within the thermal storage for charging the store using local excess electricity generation or electrical energy available from the grid. They give a rudimentary analysis of plant performance based on ideal clear sky solar days. This seems to be the only paper investigating the potential for this storage paradigm for CST; teh idea of storing electrical energy as heat warrants further investigation as it enables an arbitrage mechanism for profit making i.e. buy low, sell high. Such an arbitrage mechanism is investigated for the operation of wind farms with associated pumped hydro storage by Kim and Powell (2011b).

\section{Modelling and Optimisation: Methods Applicable to CSP with Storage}

This section presents a selection of papers related to the modelling of external parameters relevant to the operation of a CST plant. This is followed by a presentation of literature relating to the problem of optimisation of CST plant and the use of storage in general.

\subsection{External Parameter Modelling}

Power generation from a CST needs to be framed within the context of: $i$ ) the available solar resource, in terms of Direct Normal Irradiance (DNI) $i$ ) the energetic demand from the grid and iii) the economic environment.

Models for Solar Irradiation. The energy source for a CST plant is direct solar irradiance. To manage a CST plant it is important to understand how solar irradiance will vary on different time scales, including short time scales (minutes), over which irradiance can be forecast with sufficient accuracy to maintain control over the plant, and longer time scales (hours or days) depending on the energy storage capacity of the plant.

The review of solar irradiance models by Diagne et al. (2013) discusses the accuracy and the relative computational requirements for predicting solar irradiance at various time horizons along with hybrid models for the combination of both very short term and longer term predictive models.

The work performed by Huang et al. (2013) gives an hourly one step ahead predictor for global or DNI, provided there is historical training data available, using a modified time series analysis method.

Some work has also been performed to establish the diffuse fraction of solar irradiation (Boland et al., 2008) from which DNI can be inferred when only global solar irradiation historical data is available.

Models of Demand. A comprehensive review of demand modelling for use with energy production worldwide is presented by Suganthi and Samuel (2012). This review dealt with short term to long term forecasting world wide using a variety of techniques.

Techniques by Magnano et al. (2008) were used for the synthetic generation of load or demand characteristics for South Australia. Magnano and Boland (2007) was used to support this work as demand variation is largely driven by temperature, time of day, day of week and month of year. Boland (2010) builds on both these previous works with two applications, one being a PV positioning optimisation problem which also uses stochastic programming as described by Shapiro and Philpott (2007). 
Hong et al. (2011) gives a description of a complementary method for short term load prediction using multiple linear regression methods based on month, hour, and temperature as the input variables.

Models for Energy Spot Price Prediction. The revenue that can be generated by a plant will depend not only on the demand for electricity but also on the wholesale spot price, which varies every five minutes. Kim and Powell (2011a) presents a zero moment method (Robbins and Monro, 1951) for the prediction of spot price fluctuations in energy markets.

\subsection{Modelling and Analyses with Scenarios of Differing Penetration of Renewable Energy}

The report by Denholm et al. (2013) discusses in some detail the operation of a CST within a scenario of 33\% renewable energy supplier penetration. One of the main observations from this work was that with renewable energy at 33\% of the total market, CSP with storage should be operated primarily to provide ancillary services for grid frequency stabilisation and ramp rate matching in order to provide maximum value to the grid. This work utilises the National Renewable Energy Laboratory (NREL) System Advisor Model (SAM) ([Gilman et al. 2008) and (Gilman and Dobos, 2012)).

The article by Usaola (2012b) discusses similar grid stabilisation operation from a regulator or policy making perspective in the Spanish energy market with details of the model formulation and analyses presented in Usaola (2012a) for short term (2 day ahead) prediction of market behaviour (demand and price). One of the key findings of Usaola (2012b) is that the Spanish market does not present the same opportunities for returns as the US market.

A complementary report by Mills and Wiser (2012) compares the long-run marginal economic value of wind, single axis tracking PV, CSP without storage and CSP with 6 hours thermal storage in California for a 2030 scenario against the cost of operating a flat block fossil fuel generator of the same capacity, as the percentage penetration of all variable generation technologies is increased. The findings show that within the limited scope of their study, the marginal value of CST decreases less than that of PV and CSP without storage as the percentage penetration of variable generation increases and that the marginal value of CST remains higher than that of wind at all penetration levels.

The recent report "Australian Companion Guide to SAM for Concentrating Solar Power", by Lovegrove et al. (2013) presents the customisation required to NREL SAM in order for the plant operation to be evaluated in the Australian environment.

The Australian Energy Market Operator (AEMO, 2013) details a set of four case studies for 100\% RE generation based on one of two scenarios, one with rapid deployment and moderate economic growth the other with moderate deployment and rapid economic growth for projected demand in the year 2030 or 2050. Input data for the report is sourced from AEMO (2012a) and although thorough and covering a large geographic area, this study, like the others previously mentioned, uses time-sequential modelling on an hourly time scale. Furthermore, one of the clearly stated limitation to the modelling of CST in AEMO (2013) was to use all the energy stored in the previous 24 hours in the proceeding day without addressing possible consequence of this for the longer term.

\subsection{Control and Optimisation}

Optimisation of a CST needs to consider the following:

i) optimal control of an existing plant with storage systems to maximise revenue

ii) optimal sizing of collectors and storage systems.

When considering CST operation within the context of the Australian NEM energy and ancillary services markets, dispatch bids are made at 5 minute intervals with half hourly clearing cycles. Though unique to the NEM, there may be benefits in developing methods applicable to the 5 minute time frame as evidenced in the report by AEMO (2012b) where one of the improvements in forecasting wind output is attributed to performing wind data analysis on the reduced interval size of 5 minutes from the previous 30 minute intervals.

Hybrid Cars. The control of hybrid cars presents some potential parallels in that in-car ESS provide a buffer for the primary energy supply (the combustion engine) for the optimisation of total power output. Evangelou and Shukla (2012) presents a simple control system for hybrid car control with only four active states: $i$ ) Battery only ii) Engine alone iii) Engine and battery $i v$ ) Engine charging battery. This work builds on the work done by Shabbir et al. (2012) to evaluate the off-line efficiency optimum for the supervisory control based on three different driving scenarios. 
In a similar way, the control system for a CST could potentially be modelled with a small set of control modes and where the state transition thresholds would be established based on a set of typical (or even worst case) supply, demand and price profiles and then evaluated against either synthetically generated series of data or in a real time environment.

Optimisation for Renewable Electricity Generation and Storage. Bazmi and Zahedi (2011) present a substantive review of optimization studies related to power generation and supply including: “ $i$ ) Power supply and distribution ii) Power plant operation iii) Building energy consumption iv) Industrial energy consumption v) Power plants and carbon dioxide capture and storage (CCS) and vi) Renewable energy mix." A similar review by Baños et al. (2011) points to a selection of papers in each of the renewable energy generation domains mentioned in Section 2 .

Examples of Optimisation for Renewable Electricity Generation Operation. Kim and Powell (2011b) presents a method to optimise the value of storage for an wind farm with associated pumped hydro storage system. The optimisation is performed by making short term decisions throughout the day as to store or dispatch energy based on an arbitrage mechanism for revenue (i.e. buy low, sell high). This problem is a variation of the well-known news vendor problem from operations research. The method assumes quantised state of charge levels for the storage element as well as operation within the discrete time domain and is limited to one day at a time optimisation, with all stored energy at the end of the day being of no value to the next day's trading.

An optimisation of a theoretical solar trough power plant with thermal store was presented by Morin (2012) considering the multivariate objectives for economic, energetic and operational aspects. The method uses multi objective optimisation enabled via Genetic Algorithms (GA) for traversing the solution space and presents a sensitivity analysis on various aspects of the plant operation. From an economic perspective the method optimises an Levelised Cost of Energy (LCOE) parameter rather than the value that can be provided to an electricity market with fluctuating prices.. The key finding of this work is that an optimisation across all aspects of the plant, collector, power block and storage determines a better optimum that the optimisation of each of the components in isolation.

\section{CONCLUSIONS}

This paper has presented a brief summary of technologies pertaining to the implementation of Concentrated Solar Power plants implemented with both thermal energy storage and electric storage systems as depicted in Figure 1 .

The optimal operation and sizing of concentrating solar thermal plants with both thermal and electrical storage has not yet been studied comprehensively.

Two of the major findings from the identified literature at this point are, firstly that most, if not all analysis is performed on hourly time scales rather than the Australian NEM market clearance interval time of 30 minutes, nor at the bid interval of 5 minutes. Secondly, concentrated solar thermal generation with storage becomes increasingly viable as the use of renewable energy storage increases.

There are a number of opportunities for further research: $i$ ) evaluating the value of electricity buy-back into either the TES or into distributed ESS under the CST plant's direct control, $i i$ ) conducting system control at the finer time scale of 5 minutes and iii) making use of longer term weather predictions to better manage storage state over larger time frames.

\section{ACKNOWLEDGEMENT}

Luigi Cirocco would like to thank the financial supports from the School of Information Technology and Mathematics and the Barbara Hardy Institute, University of South Australia.

\section{REFERENCES}

AEMC (2013, March). National Electricity Rules: Current Rules. http://aemc.gov.au/ Electricity/National-Electricity-Rules/Current-Rules.html. Version 55, effective 13-March-2013, accessed 24 April 2013.

AEMO (2012a, September). AEMO's Modelling Assumptions and Input Report. http://www. climatechange.gov.au/reducing-carbon/australian-energy-market-operator/ aemo-input-assumptions-report/input-assumptions. Accessed 20 June 2013. 
AEMO (2012b). South australian electricity report. Technical report, Australian Energy Market Operator.

AEMO (2013, March). 100 per cent renewables study draft modelling outcomes. http://www . climatechange.gov.au/sites/climatechange/files/files/reducing-carbon/ aemo/renewables-study-report-draft-20130424.pdf. Accessed 30 May 2013.

Baños, R., F. Manzano-Agugliaro, F. Montoya, C. Gil, A. Alcayde, and J. Gómez (2011). Optimization methods applied to renewable and sustainable energy: A review. Renewable and Sustainable Energy Reviews 15(4), 1753-1766.

Bazmi, A. A. and G. Zahedi (2011). Sustainable energy systems: Role of optimization modeling techniques in power generation and supply - A review. Renewable and Sustainable Energy Reviews 15(8), 3480-3500.

Belusko, M., E. Halawa, and F. Bruno (2012). Characterising PCM thermal storage systems using the effectiveness-ntu approach. International Journal of Heat and Mass Transfer 55(13-14), 3359-3365.

Boland, J. (2010). Generation of synthetic sequences of electricity demand with applications. In J. A. Filar and A. Haurie (Eds.), Uncertainty and Environmental Decision Making, Volume 138 of International Series in Operations Research \& Management Science, pp. 275-314. Springer US.

Boland, J., B. Ridley, and B. Brown (2008). Models of diffuse solar radiation. Renewable Energy 33(4), 575 $-584$.

Cabeza, L. (2012). 3.07 - thermal energy storage. In E. in Chief: Ali Sayigh (Ed.), Comprehensive Renewable Energy, pp. 211 - 253. Oxford: Elsevier.

Chen, H., T. N. Cong, W. Yang, C. Tan, Y. Li, and Y. Ding (2009). Progress in electrical energy storage system: A critical review. Progress in Natural Science 19(3), 291 - 312.

Denholm, P., Y.-H. Wan, M. Hummon, and M. Mehos (2013, March). An analysis of concentrating solar power with thermal energy storage in a california 33\% renewable scenario. Technical Report NREL/TP-6A2058186, National Renewable Energy Laboratory (NREL), 15013 Denver West Parkway Golden, Colorado 80401.

Diagne, M., M. David, P. Lauret, J. Boland, and N. Schmutz (2013, November). Review of solar irradiance forecasting methods and a proposition for small-scale insular grids. Renewable and Sustainable Energy Reviews 27, 65-76.

Díaz-González, F., A. Sumper, O. Gomis-Bellmunt, and R. Villafáfila-Robles (2012). A review of energy storage technologies for wind power applications. Renewable and Sustainable Energy Reviews 16(4), 2154 -2171 .

Evangelou, S. and A. Shukla (2012). Advances in the modelling and control of series hybrid electric vehicles. In American Control Conference (ACC), 2012, pp. 527-534.

Fthenakis, V. and T. Nikolakakis (2012). 1.11 - storage options for photovoltaics. In E. in Chief: Ali Sayigh (Ed.), Comprehensive Renewable Energy, pp. 199 - 212. Oxford: Elsevier.

Gilman, P., N. Blair, M. Mehos, C. Christensen, S. Janzou, and C. Cameron (2008, August). Solar advisor model: User guide for version 2.0. Technical Report NREL/TP-670-43704, National Renewable Energy Laboratory, 15013 Denver West Parkway Golden, Colorado 80401 303-275-3000.

Gilman, P. and A. Dobos (2012). System advisor model, sam 2011.12.2: General description. Technical Report NREL/TP-6A20-53437, National Renewable Energy Laboratory, 15013 Denver West Parkway Golden, Colorado 80401 303-275-3000.

Hoffschmidt, B., S. Alexopoulos, J. Göttsche, M. Sauerborn, and O. Kaufhold (2012). 3.06 - high concentration solar collectors. In E. in Chief: Ali Sayigh (Ed.), Comprehensive Renewable Energy, pp. 165 - 209. Oxford: Elsevier.

Hong, T., P. Wang, and H. Willis (2011). A na ive multiple linear regression benchmark for short term load forecasting. In Power and Energy Society General Meeting, 2011 IEEE, pp. 1-6.

Huang, J., M. K. Korolkiewicz, M. Agrawal, and J. Boland (2013). Forecasting solar radiation on an hourly time scale using a coupled autoregressive and dynamical system (cards) model. Solar Energy 87(0), 136149.

Kim, J. H. and W. B. Powell (2011a). An hour-ahead prediction model for heavy-tailed spot prices. Energy Economics 33(6), $1252-1266$.

Kim, J. H. and W. B. Powell (2011b). Optimal energy commitments with storage and intermittent supply. Operations Research 59(6), 1347-1360.

Lizarraga-Garcia, E., A. Ghobeity, M. Totten, and A. Mitsos (2013). Optimal operation of a solar-thermal power plant with energy storage and electricity buy-back from grid. Energy 51(0), $61-70$.

Lovegrove, K., S. Franklin, and B. Elliston (2013). Australian Companion Guide to SAM for Concentrating Solar Power. Technical Report May, Australian Solar Thermal Energy Association (Austela).

Lovegrove, K., A. Luzzi, I. Soldiani, and H. Kreetz (2004). Developing ammonia based thermochemical 
energy storage for dish power plants. Solar Energy 76(13), 331 - 337.

Lovegrove, K. and J. Pye (2012). Fundamental principles of concentrating solar power (CSP) systems. In K. Lovegrove and W. Stein (Eds.), Concentrating solar power technology: Principles, developments and applications, Number 21 in Woodhead Publishing Series in Energy, Chapter 2, pp. 16-67. Woodhead Publishing.

Magnano, L. and J. Boland (2007). Generation of synthetic sequences of electricity demand: Application in south australia. Energy 32(11), 2230 - 2243.

Magnano, L., J. Boland, and R. Hyndman (2008). Generation of synthetic sequences of half-hourly temperature. Environmetrics 19(8), 818-835.

Mills, A. and R. Wiser (2012). Changes in the Economic Value of Variable Generation at High Penetration Levels : A Pilot Case Study of California. Technical Report June, Ernest Orlando Lawrence Berkeley National Laboratory.

Morin, G. (2012). Optimisation of concentrating solar power (csp) plant designs through integrated technoeconomic modelling. In K. Lovegrove and W. Stein (Eds.), Concentrating solar power technology: Principles, developments and applications, Number 21 in Woodhead Publishing Series in Energy, Chapter 16, pp. 495-535. Woodhead Publishing.

Robbins, H. and S. Monro (1951). A stochastic approximation method. The Annals of Mathematical Statistics 22(3), pp. 400-407.

Sayigh, A. (2012). Comprehensive renewable energy - preface. In E. in Chief: Ali Sayigh (Ed.), Comprehensive Renewable Energy, pp. $\mathrm{xx}$ - xxii. Oxford: Elsevier.

Shabbir, W., C. Arana, and S. Evangelou (2012). Series hybrid electric vehicle supervisory control based on off-line efficiency optimization. In Electric Vehicle Conference (IEVC), 2012 IEEE International, pp. 1-5.

Shapiro, A. and A. Philpott (2007, March). A tutorial on stochastic programming. http://www2. isye. gatech.edu/people/faculty/Alex_Shapiro/TutorialSP.pdf. Accessed 20 May 2013.

Steinmann, W.-D. (2012). Thermal energy storage systems for concentrating solar power (csp) plants. In K. Lovegrove and W. Stein (Eds.), Concentrating solar power technology: Principles, developments and applications, Number 21 in Woodhead Publishing Series in Energy, Chapter 11, pp. 362-394. Woodhead Publishing.

Suganthi, L. and A. A. Samuel (2012). Energy models for demand forecasting - a review. Renewable and Sustainable Energy Reviews 16(2), 1223-1240.

Usaola, J. (2012a). Operation of concentrating solar power plants with storage in spot electricity markets. Renewable Power Generation, IET 6(1), 59-66.

Usaola, J. (2012b). Participation of CSP plants in the reserve markets: A new challenge for regulators. Energy Policy 49(0), $562-571$. 